Ospina-Enciso, A.F. (2019). Fractura y abismo en la antropología actual: confrontación a la etnografía desde el "Replanteamiento del trabajo de campo" de Luis Guillermo Vasco. Revista de Antropología y Sociología: VIRAJES, 21(1), 103-129. DOI: 10.17151/rasv.2019.21.1.5

\title{
Fractura y abismo en la antropología actual: confrontación a la etnografía desde el "Replanteamiento del trabajo de campo" de Luis Guillermo Vasco
}

\section{ANDRÉS FELIPE OSPINA ENCISO**}

Recibido: 24 de abril de 2019

Aprobado: 27 de mayo de 2019

Artículo de Reflexión

* Doctor en Antropología. Profesor de la Universidad Pedagógica y Tecnológica de Colombia, Tunja, Colombia. E-mail: andesosama@gmail.com. (1) ORCID: 0000-0003-3871-2700. Google Scholar 


\title{
Resumen
}

La antropología y su método de investigación, el trabajo de campo etnográfico, han experimentado transformaciones que coinciden con los tránsitos del conocimiento social en las últimas décadas, en donde perspectivas como el multiculturalismo (Rosaldo, 2000) o el perspectivismo (Viveiros, 2010) han propuesto alternativas para el reconocimiento de la otredad. Pese a ello, las vías metodológicas de la antropología han mantenido una identidad ligada al colonialismo y han estado sujetas a una lógica vertical de la producción científica que estudia la diversidad cultural y la alteridad con fines de control y dominación. En respuesta a esta forma del quehacer disciplinar, antropólogos al margen como Luis Guillermo Vasco han propuesto alternativas metodológicas divergentes que ofrecen otros panoramas del hacer originados en las teorías y conocimientos que producen los mismos pueblos estudiados. Dicha antropología, crítica del oficio del antropólogo, es una base para indagar por vías metodológicas propias que superen el influjo de dominación cultural y el colonialismo del saber presentes en los diferentes paradigmas del conocimiento científico. Este manuscrito da cuenta de cómo la reflexión metodológica de Vasco es un insumo para pensar la producción de un estilo y un sentido propio del hacer antropología y trabajo de campo para nuestros contextos.

Palabras clave: etnografía en Colombia, crítica metodológica, Luis Guillermo Vasco, conocimiento local.

\section{Fracture and abyss in current anthropology: confrontation with ethnography from the "Rethinking of field work" by Luis Guillermo Vasco}

\begin{abstract}
Anthropology and its method of research, ethnographic fieldwork, have undergone transformations that coincide with the transitions of social knowledge in recent decades where perspectives such as multiculturalism (Rosaldo, 2000) or perspectivism (Viveiros, 2010) have proposed alternatives for the recognition of otherness. Despite this, the methodological pathways of anthropology have maintained identity linked to colonialism and have been subject to a vertical logic of scientific production that studies cultural diversity and otherness for the purpose of control and domination. In response to this form of disciplinary work, anthropologists on the sidelines like Luis Guillermo Vasco have proposed methodological alternatives that offer other scenarios of doing, originated in the theories and knowledge produced by the same peoples studied. The aforementioned anthropology, a critique of the anthropologist's purpose, is a basis for inquiring in its own methodological pathways that overcome the influence of cultural domination
\end{abstract}


and the colonialism of knowledge present in the different paradigms of scientific knowledge. This manuscript shows how Vasco's methodological reflection is an input to think the production of a style and a sense of doing anthropology and fieldwork in our contexts.

Key words: ethnography in Colombia, methodology critique, Luis Guillermo Vasco, local knowledge.

\section{Introducción}

71 artículo analiza la crítica hecha al trabajo de campo en antropología desde la perspectiva de Luis Guillermo Vasco, un autor que rechaza las formas tradicionales y contemporáneas de hacer etnografía en Colombia, así como la relación que establecen los antropólogos con las poblaciones objeto de la producción de conocimiento antropológico. Para este investigador, son solo los antropólogos (y las sociedades o instituciones que los emplean) y no las poblaciones objeto de estudio quienes se benefician con la recolección sistemática de los conocimientos locales, por el contrario, son las poblaciones objeto de conocimiento funcional para su sometimiento.

En ese orden de ideas, la etnografía no es un ejercicio de conocimiento situado o una "relación social" (Vasco, 2006; 2012) entre pueblos e investigadores que conocen en conjunto una realidad social para transformarla, sino una tecnología de dominación científica y cultural sobre esos pueblos y sus saberes. Dicha dominación se ampara en la presunta neutralidad del conocimiento científico, en tanto desarrolla un ejercicio de adquisición, posesión y traducción del conocimiento que extiende el control político y económico del capitalismo sobre las poblaciones que se reconocen como alteridad étnica y cultural. En el caso de la antropología que se hace en Colombia, de la cual Vasco es un asiduo crítico, estos problemas se refrendan en la producción académica, la formación de antropólogos y la interacción con las poblaciones que hacen parte de los trabajos en campo de los antropólogos.

Para posicionar el origen de esta posición crítica, valga indicar algunas líneas sobre la trayectoria de este investigador. Luis Guillermo Vasco fue uno de los primeros licenciados en antropología en Colombia y por más de 
40 años enseñó antropología en La Universidad Nacional así como en otras universidades del país. Esto le ha permitido confrontar con autoridad, y a veces con desdén y desencanto, las actividades de investigación del gremio. Él critica el funcionamiento de la disciplina: cuestiona el pecado original de la antropología por ser diseñada como herramienta de dominación colonial, y arremete contra la práctica antropológica actual, en un contexto donde los antropólogos investigan solo para resolver sus propios problemas y los intereses de la economía política de su sociedad (Flórez, 2004) sin comprender las realidades y problemas de los mundos donde investigan.

En sus planteamientos, Vasco no está interesado en generar una refinada clasificación nominal de campos y conceptos como sí es habitual en los antropólogos que en Colombia se han dedicado a categorizar el desarrollo de la antropología como oficio (Restrepo, 2006; Tocancipá-Falla, 2016). Por tanto, el alcance de este escrito tampoco persigue categorizar o definir los campos y conceptos "vasquistas" de forma categórica. Valga sí decir que el trabajo de Vasco ha tenido origen en la reflexión desde una praxis movida por las preocupaciones de los procesos organizativos y de las experiencias históricas de los pueblos embera, guambianos y nasas y otros grupos étnicos que van en contracorriente al discurrir de la reflexión y la práctica disciplinar canónica que se ha producido en las últimas décadas. Será por estas razones que el trabajo de Vasco ha sido valorado como una anti-antropología (Vasco, 2006).

A este autor no le interesa distinguir qué es antropología, qué es trabajo de campo o cómo la metodología es un desglose operativo de una premisa conceptual y muchos menos cómo se caracterizan o distinguen las formas del oficio antropológico. A Vasco le interesa la capacidad de actuación de los conceptos en la vida social. Para este, los conceptos cobran sentido mediante la relación de estos con los campos de acción de donde emergen los problemas de la vida social. Ahora bien, como esta aplicabilidad no ocurre en la antropología que practicamos en nuestro contexto, se produce una situación crítica: el desfase entre antropología y realidad. Para no acentuar dicho desfase, Vasco propone reactivar la relación de conocimiento desde las necesidades e intereses de los pueblos y, de esta manera, legitimar el saber y sus esquemas de significación (Vasco, 2006).

En su análisis sobre la ruta metodológica del trabajo de campo (Vasco, 2002; 2006; 2007; s.f.), el autor refleja una preocupación adicional: en el campo, las relaciones entre el investigador y los pueblos con que trabaja hacen parte de un replanteamiento global (Vasco, 2012, p. 80) donde la producción de conceptos, clasificaciones y definiciones corresponden a juicios externos al contexto del que emergen. Como contrapropuesta, Vasco afirma que el investigador debe ajustar sus criterios a las condiciones 
y expectativas de la realidad que pretende indagar. La producción de conocimiento comienza no con la adopción de conceptos externos al contexto sino con la emergencia de conceptos propios, originarios del mismo mundo de ideas y prácticas que se quiere investigar.

Su afirmación no se limita a considerar la clásica distinción entre categorías emic o ethic que toma la antropología para discriminar entre conceptos emergentes en el trabajo de campo de conceptos contenidos en paradigmas disciplinares. Vasco reconoce la función y utilidad de una relación vital, pero despreciada por el conocimiento antropológico, a saber, el vínculo entre los conceptos y las cosas en su contexto social, en la vida de la cual surgen. Por eso se interesa en el desenvolvimiento de los conceptos$\operatorname{cosa}^{1}$, en la materialidad y el sentido que contienen la historia y las prácticas del día a día en pueblos y territorios por los que el investigador -que es tanto el indígena, el afro, el campesino o el solidario que acompaña- camina en tanto recoge "los conceptos en la vida".

Una de las cosas que a mí no me gusta y que a los antropólogos les fascina es poner nombres distintos a las cosas para decir "mire cómo estoy aportando yo" y "mire que creé tal concepto", pero a veces toca. Para el libro Entre selva y páramo, usé un concepto que llamé, como metodología de investigación, "recoger los conceptos en la vida". Se supone que eso es lo que creé en el trabajo conjunto con los indígenas, no yo solo. (Vasco, 2006, p. 20)

La metodología y la ruta del trabajo de campo surgen de las necesidades y apuestas que requiere el mundo social que se indaga, de allí emerge el qué y el cómo investigar. Dicha orientación debe surgir de las condiciones e intereses de los actores que viven su realidad y producen su saber. Si la antropología no camina en esa tónica el trabajo de campo seguirá atado a las lógicas de poder y dominación.

Para Vasco la reformulación -o en sus palabras, el replanteamientodel trabajo de campo y de la escritura en antropología deben funcionar a la manera de una contrapropuesta, una metodología a contracorriente de los esquemas funcionales, del empirismo positivista y del discurso impersonalizado y ajeno de la realidad que proponen las teorías críticas de

\footnotetext{
${ }^{1}$ Son elementos de la vida diaria que contienen un sentido del mundo en donde son elaborados, implementados y comprendidos en tanto hacen parte de una lógica de mundo. Sobre su experiencia con los guambianos Vasco (2007) dice que: "Todos estos elementos concretos [los conceptos-cosa] con los cuales los guambianos piensan la realidad y la explican, la comprenden y la transforman, son elementos presentes en su medio y en su vida cotidiana; por ello, a diferencia de lo que ocurre con los nuestros, los conceptos guambianos no están en los libros, ni en las cabezas de la gente, que se los ha metido en ella a partir de los libros, sino que están en la vida cotidiana" (p. 37).
} 
la cultura, pues ninguna de estos enfoques resuelve el vacío que prevalece entre realidad y conocimiento.

\section{Discusión}

\section{La formación y el pecado original del etnógrafo: el rechazo y/o la aceptación de una disciplina}

Junto a la crítica a la práctica antropológica, otra detracción vasquista se sitúa en un nicho no menos complejo, el salón de clase y la formación de antropólogos en el trabajo de campo. Los antropólogos que nos formamos después de que Vasco dejara la Universidad Nacional en 2003, sufrimos del mismo mal que él cuestionó a sus estudiantes y por el cual, entre otros asuntos, dejó la docencia.

Para Vasco los estudiantes de antropología, los de antes y los de ahora, somos profesionales de las circunstancias, es decir, adaptamos nuestro discurso disciplinar, nuestra acción política y nuestra perspectiva de investigación a la moda temática o tipológica, a la exigencia del mercado laboral y al ingreso lucrativo más conveniente. Dichas situaciones por lo general no concilian con las condiciones y necesidades de las poblaciones objeto de interés del antropólogo. Esto quiere decir que en el contexto de formación del antropólogo priman condiciones materiales de existencia que hacen de los profesionales de la disciplina y de los programas de los que se gradúan, reproductores de condiciones sociales de dominación y explotación que en lugar de producir transformaciones, se reafirman con la operación acrítica de los profesionales en antropología.

Para Vasco esto es consecuencia del entramado histórico que compone la producción y enseñanza del conocimiento antropológico. El conflicto de base o pecado original de la disciplina, a saber, su impronta colonial, ha condicionado la funcionalidad de la formación disciplinar. La situación iniciática a la que se somete un estudiante "primíparo" de antropología amolda su prospecto profesional a las condiciones de la cultura occidental a la que pertenece, aun cuando éste busque extrañarse de esa realidad dominante a partir del conocimiento del "otro".

El estudiante que llega a estudiar "la ciencia de la cultura" aterriza en un programa de antropología buscando elementos para comprender su rol y el de su mundo en el juego de las relaciones sociales y culturales. En esa búsqueda cuestiona su situación como individuo e indaga por las relaciones posibles entre la sociedad occidental y la otredad. 
Sin embargo, en el primer curso de etnología que curse encontrará que su disciplina es un manojo de actitudes y prácticas colonialistas, pues las políticas de extensión y dominación imperial sobre el otro colonizado han diseñado las estructuras conceptuales y también metodológicas de las que se compone la disciplina antropológica.

El desencanto, producto de sentirse parte de un proyecto colonial de conocimiento es "aliviado" por el plan de estudios y sus cursos sucesivos, sin mucha demora. Las relaciones de dominación han sido institucionalizadas, y con el desarrollo tecnócrata (Tocancipá-Falla, 2016) de la antropología en universidades alrededor del mundo el pecado original se ha disipado. Adicional a esto, el desarrollo de nuevos discursos como el multiculturalismo, el decolonialismo, el perspectivismo, entre otros, propicia un nuevo aire de comprensión y reconocimiento de la alteridad.

Además, los planes de estudio hacen eco de nuevas tendencias que alejan a la disciplina de ese pasado culposo. La antropología para la dominación se enseña como un pasado vergonzoso, pero al fin pasado que no objeta la práctica y la enseñanza de la antropología contemporánea. Reflejo de estos son los planes de estudio en antropología que han incorporado a las mallas líneas de profundización en temas comola memoria, los movimientos sociales, los estudios ecológicos o ambientales, este es el caso de programas nuevos como los de la Universidad ICESI, o las líneas de investigación y profundización de los programas de antropología de la Universidad Nacional, Universidad de los Andes y Universidad del Cauca, entre otros. Dichas transformaciones en los planes de estudio, además de proponer nuevos paradigmas formativos, también plantean un ejercicio de diferenciación consciente con cualquier atisbo de esa antropología primigenia, hecha para la dominación que impulsó el imperio británico o los propósitos expansionistas de la Rusia de Catalina II. El proyecto ideológico y colonial que encarnó la disciplina ha sido revaluado por las antropologías dialógicas e interpretativas que, sostenidas en una pedagogía del encuentro (Godenzzi, 1999), incorporan en la producción de saberes a los sujetos de la alteridad y sus narrativas, que otrora eran los objetos de dominación.

Sin embargo, Vasco arguye que tal reconocimiento en la antropología contemporánea del otro no es ni cierto ni concluyente. Si bien el estudiante aprende que la antropología actual ya no es colonialista porque su cuerpo discursivo reconoce al otro como un actor con prácticas y narrativas comprensibles antes que dominables, los planes de estudio todavía contienen y enseñan varias prácticas de corte colonial al momento de hacer etnografía, incluso cuando el discurso contemporáneo rechaza o trata de evitar este tipo de lógicas. Para comprender este punto, la 
práctica metodológica y el saber hacer del trabajo de campo son elementos clave, veamos.

La etnografía clásica, sostenida en el trabajo de campo y el acceso sistémico a la vida de los otros en una "inmersión total" -la zambullida de la etnografía de Malinowski (1986) - ha sido la metodología característica del trabajo del antropólogo. En los "Talleres de técnicas etnográficas" y los "Laboratorios de investigación social" se aprenden a hacer los registros del diario de campo y a compilar y desglosar la información privilegiada a la que accede el testigo directo. Se aprende a recoger y trasferir información de la que se nutre la disciplina como ejercicio científico.

Dicha práctica ha sido cuestionada en los últimos tiempos por paradigmas de las ciencias sociales que cuestionan el cómo se obtiene y el qué se hace con la información que emerge de los pueblos con los que trabaja el etnógrafo. A esta perspectiva se reconoce como la etnografía crítica, esta cuestiona el trabajo de campo que desarrolla la etnografía clásica y lo considera como una práctica invasiva (Foley y Valenzuela, 2005). Para sus críticos, la etnografía clásica arremete contra las formas locales de identificación y conocimiento, y en tanto, desconoce los modos propios y los significados locales, todo esto so pretexto de atrapar los imponderables de la vida social. En contraste, la etnografía crítica plantea que una articulación entre el estudio de la cultura y las relaciones de poder es necesario en los propósitos de transformación de la realidad social desde un ejercicio crítico y reflexivo por parte del etnógrafo que lo haga partícipe de los procesos de activismo y liberación de los marginados (Vargas, 2016).

Vasco hace un cuestionamiento a las etnografías, tanto a la clásica como a la que cuestiona a la clásica, aun cuando comparte algunos puntos de vista con la etnografía crítica. Para ello hace uso de la agudeza, la mordacidad y también de un estilo de confrontación característico de su trabajo y formula tanto la crítica como la contrapropuesta.

[...] En lo fundamental, a lo largo de la historia, o de su historia, la etnografía ha servido para la dominación, la explotación de los pueblos y, para el caso nuestro, en lo esencial, de los indios; aunque a raíz de la constitución del 91 los negros comenzaron a pedir que la antropología sirviera también para dominarlos y explotarlos a ellos, y se quejaron porque no había sido así.

[...] Sobre esa base hay otro criterio y es que la etnografía debe dejar de ser un instrumento de esos dominadores y explotadores y convertirse en un instrumento de los dominados y los explotados en su lucha contra esa dominación y esa explotación y, en el caso concreto que me corresponde, las que hay sobre los indios. (Vasco, 2007, pp. 20-21) 
Ante la propuesta conceptual y metodológica sobre el otro que propone las distintas perspectivas de la antropología contemporánea -que parecen ser la redención para saldar los previos pecados conceptuales y de método de la disciplina-, Vasco manifiesta reparos y desconfianzas respecto a esa apertura o reinvención, pues la forma contemporánea de hacer antropología genera alertas y suspicacias respecto a las formas de conocer y representar sobre $e l$ otro pero no con éste.

Vasco advierte que este desfase tiene asidero en las relaciones de dominación y sujeción económica que imperan en la sociedad capitalista de otrora y actual. De estas la antropología es un síntoma efectivo. A Vasco le llama la atención el estrecho y continuo vínculo que hay entre la producción de conocimiento y las tecnologías de control de la sociedad capitalista que aprenden a reconocer al otro -cultural y económicamente hablando- como forma de desarrollar sus fines de sujeción y dominación. El capital busca identificar y adherir consumidores (Flórez, 2004) mediante una empresa de asimilación y traducción favorable a éste. En dicho contexto, el etnógrafo funciona como un conector entre capital y conocimiento, un puente entre la comprensión de las relaciones que se producen en la vida cotidiana y la representación de éstas en diseños y fórmulas útiles para la acumulación y la distribución asimétrica del capital.

Ahora bien, cuando el antropólogo está inmerso en esa relación entre conocimiento y capital, su actuación se ciñe al tipo de aprehensión que ese capital requiere y a las prácticas económicas favorables al conocimiento mercantilizado. En este sentido, mientras el conocimiento sea un objeto producto de las relaciones con el capital tendrá una función asociada al mantenimiento del sistema económico del cual se desprende. Para Vasco, la formulación conceptual y metodológica en antropología no es ajena a esta lógica, incluso en su versión más dialógica e interpretativa.

A Vasco no le interesa hacer apreciaciones particulares sobre quiénes afectan a los pueblos indígenas con sus reinventadas maneras de hacer etnografía. Acaso le interesa cuestionar a quienes se cruzan en la historia de su hacer etnográfico y repeler todo intento novo por hacer etnografía que aunque remozada, sigue a su criterio siendo colonialista e inserta en arbitrarias relaciones de dominación manifiestas en el trabajo de campo. Por eso cuestiona las agendas cada vez más limitadas para hacer trabajo en terreno. Los antropólogos de hoy, so pretexto de recursos limitados y menos disponibilidad de tiempo, se dedican a rápidas y fragmentadas apariciones en los lugares donde hacen sus campos. En sus visitas tratan de agarrar los imponderables -y quizá los imposibles- de la vida social por medio de maratónicos registros centrados en los tópicos que interesan al antropólogo -no a las poblaciones- y que encuentran en los representantes 
o líderes de las poblaciones la voz autorizada para identificar el total de un significado y conocimiento social más útil al antropólogo que a la población que participa en el estudio.

Esta práctica de extracción de información contra el tiempo, que pone su énfasis en una superproducción acelerada de recolección y sistematización -que es también un proceso de acumulación de capitalno da pie para análisis profundos, sensibles a las relaciones entre los actores de la investigación y menos para compromisos con los pueblos, sus necesidades, intereses y reivindicaciones por los que sí es pertinente investigar.

De esta manera, el discurso del reconocimiento de esas voces otras, que insiste en la participación de los actores locales en la producción de sus propias narrativas pero que no brinda las condiciones materiales para su realización, se soporta en una relación de producción y rotulación del conocimiento, de carácter fetichizante y anclada al capitalismo contemporáneo. Esto ocurre como una fractura, una fractura real y permanente entre los antropólogos y los pueblos objeto de investigación que contradice el supuesto reconocimiento discursivo que desde los tiempos del pecado original de la etnografía jamás se ha dado.

\section{La relación campo-investigador y su comprensión disfuncional en el marco etnográfico}

La crítica arriba expuesta es el lugar del que parte Vasco para plantear su propuesta de trabajo de campo. La misma está ligada a una tarea de transformación de la realidad y es pertinente para las sociedades que reclaman una práctica investigativa en contexto, que se formule desde sus perspectivas y comprenda su mundo. Con estas es que toma cuerpo un trabajo etnográfico vinculante. Si esto se toma en cuenta tiene sentido escudriñar en la forma y los alcances del método.

La etnografía es una práctica que se debate entre posiciones divergentes de las que participan los actores de conocimiento. Por un lado, el etnógrafo, actor que indaga la lógica de sentido de un grupo social, y que además es autor de reflexiones y contenidos producto de la relación de indagación y conocimiento que establece con dicho grupo. De otro lado, esa participación del etnógrafo depende de las condiciones en que los pueblos objeto de análisis producen su conocimiento y de la participación social y política que tengan estos grupos con las agendas de investigación. 


\section{La crisis del estilo}

En el contexto colombiano, la antropología ha oscilado entre distintas influencias a la hora de definir los alcances de la investigación etnográfica. A dicha fluctuación Tocancipá-Falla (2016) la define como la crisis entre paradigmas que se intersecan en la construcción de un estilo, o de varios estilos, presentes en el ejercicio de la antropología colombiana. Propuestas como las de la "Antropología del debate" de Jaime Arocha, o la "Co-ciudadanía" que propone Jimeno (2004) para Latinoamérica, en donde el investigador emerge del mismo universo y de los mismos problemas que investiga, dan cuenta de un estilo de pensar y articular el trabajo de estas academias que difiere del de las denominadas antropologías nor-atlánticas.

Este cuerpo de propuestas "alternas" centra su papel en las especificidades que tienen el trabajo del antropólogo en un contexto periférico, fuera de las academias del centro. Por tanto, las preocupaciones del etnógrafo aquí no son las mismas que las de un antropólogo con origen y trabajo en las metrópolis del conocimiento y el capital. Sin embargo, estas corrientes de antropología desde el sur, centrales en los estudios sobre la antropología de la antropología en Colombia, no referencian, ni citan y menos dialogan con la anti-antropología que propone Vasco.

En su lugar, es el mismo Vasco quien menciona a Myriam Jimeno y Jaime Arocha, entre otros, para cuestionar la capacidad de compromiso y de comprensión que tienen estos antropólogos, que no han propuesto una agenda crítica e integrada con los intereses de los grupos con los que han hecho sus investigaciones. Para Vasco, estos académicos de la periferia apenas han sabido jugar el juego académico alineando su trabajo con el boom del reconocimiento pluriétnico en Colombia después de la Constitución de 1991 que, dicho sea de paso, no fue logro de estas antropologías.

Por tal razón, Vasco no considera oportunos los trabajos antropológicos de sus colegas, pues la investigación que se hace en las universidades -y por fuera de ellas también- solo beneficia el reconocimiento e intereses de expertos que no más hablan sobre otros para reafirmarse a sí mismos como expertos intelectuales.

Lo que cuestiona aún más el trabajo de la antropología en Colombia son sus referentes. Muchos antropólogos en Colombia se ciñen a las tendencias foráneas, bien sea porque los referentes de más peso en la formación y la reproducción de estilos metodológicos son externos, o porque los antropólogos que se han formado en Europa y Norte América -y en los últimos años también en universidades de Colombia con posgrados en antropología- responden a agendas conceptuales y metodológicas 
alineadas con los intereses de formación e investigación de las metrópolis del poder y del conocimiento.

En los últimos años, destaca en las agendas de investigación nacional una marcada influencia de los discursos decoloniales (Restrepo y Rojas, 2010), los estudios sobre la memoria, el giro ontológico y la antropología no antropocéntrica, los estudios hermenéuticos sobre las transiciones políticas (Castillejo, 2017; Castillejo y Reyes, 2012), y el efecto de las narrativas y de las representaciones en los procesos de identidad y reconocimiento cultural (Jimeno, Pabón, Varela y Díaz, 2016). Estas tendencias aunque implementadas en el contexto local, son acuñadas fuera y han sido concebidas para cubrir, con perspectiva foránea, la investigación y el análisis de los problemas locales.

Varias de estas vanguardias han optado por distanciarse del trabajo de campo y su base metodológica por considerar que las prácticas de la evidencia directa y del estar allí, son formas de colonización del saber que reproducen lógicas de autoridad -en términos de dominación, pero también de autoría- y traducen valores del colonialismo, así como tecnologías de control útiles para extraer el conocimiento sin contexto de las poblaciones objeto de estudio.

A este tipo de teoría social le incomoda el canon metódico de la inmersión total en las formas de vida de los otros y no acogen proximidad del investigador con las movilizaciones y aspiraciones sociales de los grupos en que se centra el interés analítico. Por tal razón, el método de trabajo opta por escudriñar el discurso, por el testimonio selectivo, que logra proximidad con el significado mas no con el actor; el discurso da cuenta de percepciones, pero no tanto de existencias vívidas.

Esto no quiere decir que el discurso y su interpretación sean inviables a la hora de comprender los fenómenos y realidades de los actores sociales, o que sean estériles a la hora de comprender y transformar sus vidas. Los estudios sociales contemporáneos dan cuenta de cómo los discursos construyen y transforman realidades (Escobar, 2007), pues estos no son solo síntomas sino constituyentes de la vida social. El conflicto de la preferencia por el análisis discursivo radica en que su significado está ausente de significante. Esto es, que los discursos que pretenden dar cuenta del mundo social suelen ignorar la composición y el sentido del mundo del que emerge dicho discurso.

La clásica composición del trabajo de campo etnográfico que propuso Clifford Geertz en la que el etnógrafo busca dar cuenta de "qué es lo que la gente dice, qué es lo que la gente hace, y qué es lo que la gente dice de lo que hace" pierde influencia en un escenario que privilegia el discurso como 
elemento de comprensión que no apuesta por un interés genuino en la vida y los problemas del otro.

En su lugar, la lógica del conocimiento de la vida social se transfiere a una comprensión de "qué es lo que el discurso dice y hace sobre las personas", aun cuando las personas no estén directamente vinculadas a la producción de un discurso o a los significados implícitos que estos contengan o elucubren. En tal sentido, el trabajo de campo se desdibuja y queda relegado por el discurso, otra tecnología del conocimiento que tampoco resuelve el problema de la legitimidad y autoridad del conocimiento de los pueblos.

\section{Estilos de conocimiento y dominación en etnografía o la emergencia de vías metodológicas propias}

El distanciamiento de las metodologías de investigación in situ, que profundicen en las condiciones y significados de la vida local y que optan por el trabajo de campo intensivo es una tendencia en los programas de antropología en Colombia. Esto se debe a las críticas hechas a los trabajos etnográficos por considerarse tecnologías de objetivación y dominación colonial, pero también por el desinterés que presentan los programas de investigación de identificar el actor social en su contexto de vida, en sus propias circunstancias.

Además, en la antropología de los tiempos actuales, el ejercicio etnográfico no necesariamente contribuye a la validación de conocimientos locales y menos a la resolución de problemas o necesidades de las poblaciones investigadas. A esto se añade que motivaciones conceptuales y metodológicas que revitalicen la etnografía y su impacto sobre las poblaciones con que trabaja no se vislumbran. Para Caviedes (2013), el trabajo de campo ha tenido una escasa influencia en los actores sociales marginados que experimentan procesos históricos de dominación y marginación.

Como alternativa y excepción a esta tendencia, Vasco ahonda desde su práctica y reflexión en los trabajos de investigación colaborativos con las luchas de reivindicación y transformación social. Tal fue el caso de "Los solidarios", una propuesta que surgió en el contexto de las movilizaciones sociales de los pueblos indígenas del Cauca de los años ochenta, como apoyo de actores no indígenas a los procesos de reivindicación social, territorial e histórica de paeces y guambianos.

Este proceso, que también se le conoció como la investigación de doble vía, es de los referentes que se encuentran en la argumentación de Vasco a la hora de afirmar que la investigación etnográfica debe surgir de las apuestas de los pueblos, quienes son los principales investigadores 
de sus realidades, y también de los externos, que cumplen una función de colaboración e identificación de los problemas de estos pueblos, pero siguiendo los criterios que los mismos pobladores establecen. Así el colaborador no es solo un observador quien registra o atestigua, es un actor social con capacidad de acción y transformación de realidades en plena relación con los preceptos que emergen del campo de investigación.

No obstante, el trabajo de los solidarios -que hay que decir, en su gran mayoría no eran ni académicos ni antropólogos-, no repercutió de forma significativa en la agenda de la antropología colombiana pues esta disciplina no se ha interesado por reconocer los otros mundos en los que dice afianzar su práctica. Por tanto, el conocimiento y el estilo metodológico de la antropología reproducen su carácter fundacional y toma distancia de las realidades sociales para solo involucrarse con los otros mediante la adquisición sistemática -o extracción- de saberes que no son suyos, pero que usurpa con el pretexto de reflexionar y comprender los mundos diversos a partir de juicios y estilos eminentemente disciplinares.

En las etnografías de lo inmediato y la producción del conocimiento antropológico la operación extractiva ocurre de manera soterrada. El etnógrafo no aparece ante sus investigados como un sujeto dominante, sino como un agente mediador de conocimientos e interpretaciones. Sin embargo, su práctica es celosa y su tacto ligero para advertir cuándo su discurso se impone sobre los conocimientos y las trazas vitales del otro, esa es la lógica que presupone la etnografía del contrato o de la producción académica eficiente y vertical. El etnógrafo no cree lo que le dicen los otros, y anula los juicios de aquellos mediante categorías apriorísticas que ha aprendido en el entrenamiento argumentativo de la academia. Como no cree, tampoco tiene sensibilidad suficiente para confrontar los conocimientos y situaciones de los pueblos que estudia, tan solo los atestigua, los relativiza y con la impronta de su escritura los desfigura. Por último, la escritura se vuelve el cómplice de esta velada simulación de apropiación de la realidad social, pues el discurso presente en el texto es retórico en participaciones, en co-costrucciones y en pluralidades que parecen ser una norma de redacción frecuente en la literatura social colombiana aun cuando la producción y la autoría sean excluyentes con las realidades colectivas.

\section{Función colonialista y objetivista en etnografía y su contrapropuesta}

No es casualidad que los lugares de la investigación etnográfica coincidan con los sitios que han sido objeto de la explotación colonial en Colombia. A lo largo de lugares periféricos las formas del trabajo etnográfico han coincidido con actividades extractivas y de dominación 
territorial y cultural. Tampoco es casualidad que hoy día las agendas de los antropólogos y los programas de investigación coincidan con los lugares que interesen a la explotación económica y a las formas contemporáneas de dominación sobre recursos, pueblos y territorios.

Vasco (2002) afirma que el colonialismo es una relación económica y política que parte de una división o enajenación de la realidad, así como del conocimiento mediado de otros que no son como nosotros. La forma en que se consolida ese conocimiento y control sobre el otro se da mediante la objetivación; esta es una percepción que delimita y categoriza a una población objeto de estudio, así como a la realidad que la comprende.

Esta delimitación es entendida por Vasco (2002) como la cosificación de la realidad indagada. Dicha cosificación da pie al control y la segmentación de esa realidad por parte de quien objetiva. La objetivación, y en consecuencia el ejercicio de dominación, es realizado por la sociedad dominante sobre sociedades diferentes a esta. En ese contexto, la sociedad capitalista aprende a conocer a otras para el desarrollo de sus propios fines, por eso para Vasco la objetividad en antropología es una trampa mortal.

Como afirma Jean Copans, la antropología ha hecho suyo como objeto de estudio el campo empírico del colonialismo, de los pueblos, etnias o nacionalidades subyugados y explotados. Es decir que mientras la expansión capitalista por el mundo despojaba a infinidad de sociedades de su carácter de sujetos de su propia historia, de su autonomía y posibilidad de vivir de un modo propio, haciéndolos receptores pasivos de una historia ajena y decidida en las metrópolis, objetos de la historia universal capitalista, la antropología hacía lo propio en el campo del conocimiento.

De entrada, se declaró inválido el conocimiento que estas sociedades tenían de sí mismas y de su entorno, se postuló su incapacidad de producir un conocimiento valedero de sus formas de vida, de las leyes que las rigen, y se llegó hasta negar el derecho a su existencia como sociedades y culturas diferentes. Se afirmaba: solo la antropología puede producir un conocimiento adecuado de ellas; sólo el discurso de Occidente puede ser científico. Oigamos a Malinowski: “La clave para interpretar la cultura no la pueden ofrecer los informadores nativos porque ellos la desconocen conscientemente. Es más adecuada la visión que ofrece el antropólogo". En ese sentido, objetividad es reducir a las sociedades estudiadas por la antropología a la calidad de meros objetos de conocimiento, despojándolas de su propia subjetividad, negando su capacidad de autoconocimiento, irguiendo frente a ellas al sujeto que conoce: antropólogo. (Vasco, 2002, párr. 7)²

\footnotetext{
${ }^{2}$ Tomado de http://www.luguiva.net/libros/detalle1.aspx?id=269\&l=3
} 
Para conocer de manera objetiva, el etnógrafo funciona como un mediador que produce la conexión entre el mundo imaginado y el mundo objetivado, que finalmente es el mundo dominado. Esta relación es producto de la participación del capitalismo en el conocimiento de los grupos sociales que están bajo su control, pues este asume que el conocimiento objetivo es un bien susceptible de intercambio. A esta situación se contrapone otra agenda, la que plantea que son los mismos pueblos dominados los que deben movilizar sus procesos de conocimiento.

Para Vasco, los pueblos indígenas deben conocerse a sí mismos y en sus propios términos, partiendo de sus propios problemas y expectativas para desarrollar procesos de investigación afines a sus intereses colectivos. Los pueblos dominados deben también analizar su relación con el entorno de la sociedad nacional y el campo de relaciones y tensiones en el que estos gravitan.

En consecuencia, y para responder a esta "trampa mortal", Vasco propone un modo de conocimiento sensible a la realidad y condiciones de los pueblos objeto de conocimiento. Esto es, alternativas metodológicas que recalen en las condiciones de vida y los conocimientos propios de esas poblaciones. Su propuesta plantea que la descripción de la realidad es una teoría del mundo, producida no por quien observa sino por el mismo mundo que es objeto de observación, de allí que todo trabajo de investigación ha de partir de una vinculación directa con estas lógicas situadas de conocimiento.

Quien mejor da cuenta de la realidad mencionada es la propia sociedad que crea, organiza y moviliza su conocimiento. En consecuencia, el antropólogo no necesita reivindicar a nadie ni hablar por nadie, pues cada grupo social se reivindica y se reconoce en su práctica. Vasco no cree en el rol del antropólogo vocero que re-significa e interpreta la voz de los otros.

Es problemático que los antropólogos se dediquen a pensar por el mundo de otros y que lo comuniquen como de su autoría. Vasco es un convencido de la traición y ficción tergiversada que cometen las interpretaciones de los antropólogos y sus ejercicios de representación sobre los discursos de los otros. El antropólogo no puede ser el transmisor ni el representante de una cultura a otra porque éste no es un actor que produce conocimiento con las personas y con la realidad que investiga. Mientras este tipo de imposición subsista, el antropólogo solo será el representante de sí mismo y del proyecto de dominación cultural que representa.

A esta perspectiva la alimenta el cambio paulatino en las condiciones de interacción y respuesta de los pueblos indígenas y de otras formaciones sociales alternativas con el sistema de desigualdades económicas y políticas en el que se encuentran insertos como actores sujetos de dominación. 
En los últimos años, la comprensión de estas circunstancias en el escenario de la alteridad, se ha centrado en la producción de un sentido histórico propio que responde a las necesidades de reconocimiento, de producción histórica y espacial, de la valoración de los procesos colectivos y de la reivindicación política que tienen estos pueblos (Rappaport, 2000; Gros, 2000; Sandt, 2013).

Esto ha sucedido porque los pueblos dominados han creado sus propias reivindicaciones políticas $\mathrm{y}$, a partir de estas, han generado procesos de auto-reconocimiento, programas de investigación y metodologías propias que producen conocimiento de forma endógena. Ejemplo de esto son los procesos de investigación sobre la historia del pueblo guambiano y la recuperación de esta como un elemento de movilización política y recuperación de tierras en el suroccidente de Colombia (Dagua, Aranda y Vasco, 1998). Es en estos procesos -y no en la academia- que la acción de los grupos de solidarios encontró eco y capacidad de trabajo y análisis. Es en este tipo de experiencias que la antropología y la investigación etnográfica toman forma de herramientas que inciden significativamente en la transformación de realidades.

Sin embargo, las ciencias sociales contemporáneas no creen en los procesos de autonomía en la producción del conocimiento y mantienen el sesgo de dominación y control sobre el otro. Para el análisis social temas como las diferencias de clase, etnia y tenencia territorial son tópicos trabajados de forma intensa pero a la vez insensible y distanciada. El alter sigue siendo un desagregado, un sujeto desprovisto, que no tiene lugar ni materialidad en la autoría del saber científico.

En esas relaciones sociales de exclusión y dominación, quien lleva la peor parte son los pueblos indígenas a quienes Vasco (2002) llama los parias entre los parias. Como respuesta, Vasco se interesa por las condiciones en que los indígenas organizan sus procesos de auto-conocimiento y por la participación de los investigadores sociales en las apuestas colectivas de estos pueblos. Con esto se pregunta ¿Qué significa hacer investigación entre estos grupos sociales? y ¿Cuál es el tipo de posición genuina que asume el investigador en esos procesos?

Las relaciones idóneas entre los etnógrafos y las comunidades comprenden un estilo donde el etnógrafo no es el portador de la autoridad (y autoría) en la investigación, sino donde es un actor de diálogo, que produce conocimiento en conjunto con los actores sociales. Este conocimiento no necesita ser transmitido o devuelto porque desde el primer momento la investigación se desarrolla por los mismos actores sociales de los que surgen los problemas a investigar. En consecuencia, dicho conocimiento se produce y analiza en la misma realidad de la que emerge. 
Es de los campos que emergen los temas de estudio, y no al revés. Si se privilegia la participación de la realidad en la agenda de investigación hay un impacto favorable en el desarrollo de la relación sujeto-objeto, pues aquí el sujeto es quien da cuenta del sentido y calidad de la realidad que analiza, en lugar de objetivarla y reducirla a dimensiones analíticas, como es lo tradicional en las ciencias sociales.

\section{Modernidades otras}

La autonomía delos pueblos dominados, sus procesosdereivindicación social y política se insertan en la emergencia de lo que algunos analistas llaman las otras modernidades (Restrepo, 2011) o modernidades indígenas (Gros, 2000). Estas son procesos de apertura donde los pueblos étnicos crean sus propias agendas y concepciones sobre lo moderno produciendo un diálogo con la sociedad mayoritaria y otras etnicidades, generando adaptaciones, transformaciones y respuestas que hacen funcional la perspectiva de lo étnico en medio de un mundo hegemonizado, con escasos espacios de participación y reivindicación.

No obstante, dicho reconocimiento no se debe a la oferta o apertura epistemológica de la ciencia antropológica. Para Vasco, las conquistas de los pueblos indígenas (otros hablarían de sus construcciones de modernidad) se deben a la lucha y a los procesos de conciencia y producción de conocimiento que han surgido desde las poblaciones en contra de sus dominadores.

Son los pueblos indígenas quienes desarrollan una práctica, una forma de ser y pensar que es considerada como práctica moderna, emergente de lo indígena. Es por medio de estas relaciones que las poblaciones étnicas reconocen quién es el otro y cómo debe ser el diálogo y la confrontación a desarrollar con éste. Producto de esta interacción es posible conocerse desde sí, junto a su posición e identidad.

Ante el carácter objetivo del proceder investigativo y el funcionamiento tradicional de la etnografía como artefactos de dominación, los pueblos indígenas han dado cuenta de su capacidad como actores de conocimiento. Estos producen reflexiones, maneras de ver y de indagar para auto conocerse, pero también para conocer quiénes son los otros, los que están al otro lado del cuadro de alteridad, y cómo estos han producido realidades vinculadas a lógicas de dominación, así como las afectaciones que generan en el devenir de los pueblos indígenas y sus alternativas. En esto consiste, desde la perspectiva indígena, el trabajo de investigación en doble vía que Vasco resalta. 


\section{La acción práctica y transformadora del conocimiento desde los "dilemas" éticos}

Desde su posición como marxista maoísta, imbricado en la teoría de la praxis, todo conocimiento que se desarrolle no tiene para Vasco mérito alguno si no se dirige a la transformación de la realidad de la que es producto. Para hacer una transformación es necesario un entendimiento entre los actores que producen dicho conocimiento. A dicho encuentro, Vasco lo denomina "la confrontación del conocimiento". Ocurre a través de una relación de diálogo y de relacionamiento entre actores con diferentes posturas y planteamientos que coinciden en una realidad práctica y en un sentido histórico vinculante con el que los diferentes actores se relacionan. Por tanto, el conocimiento, además de ser práctico debe hacer parte de un ejercicio de comunicación y reciprocidad. Debe recalar en un sentido de lo ético.

Producto de esos lazos y comunicaciones se ensamblan intereses comunes entre los indígenas y la sociedad a la que el investigador pertenece. Para Vasco, hay en esta relación un tema central: el compromiso actuado del investigador. Sin embargo, el investigador típico supedita su actuación a un canon de lo permitido y de lo no sancionable acordado por la comunidad científica a la que pertenece. Dicha valoración sucede sin distinción de otros referentes éticos distintos a los de su comunidad profesional.

Para Vasco, el rol y compromiso que cumplen dichas regulaciones y normativas en el investigador -consideradas como ética de la investigacióndejan cabos sueltos que la teoría contemporánea ha hecho todavía más difusos. Los actos políticamente correctos del reconocimiento discursivo del otro y de las formalidades burocráticas -dígase consejos, comités de éticas, consentimientos informados, entre otros- no se involucran con las condiciones y formas éticas propias de los grupos objeto de estudio, por tanto el sentido de lo ético no es relacional y menos funcional.

Para este autor, los comités éticos de investigación de las universidades solo toman en cuenta las afectaciones que desde la perspectiva del investigador tienen lugar, y no se fijan en los impactos que tienen los programas de investigación desde el criterio de los actores impactados por la pesquisa. Los postulados de "no afectación de los sujetos objeto de investigación" dejan de lado cuestiones esenciales. Por ejemplo, a las personas que se tienen en cuenta para medir el impacto de una investigación, por lo general no se les pregunta si les interesa o encuentran pertinente una investigación de la que ellos sean el centro de interés.

La consideración ética es, en cierto modo, una carga artificial que no resuelve el desfase entre la producción de conocimiento y la afectación 
generada por este en la realidad social de los pueblos estudiados. En la antropología, dicho problema es más crítico porque "[...] ha tomado como suyo el campo empírico del colonialismo" (Vasco, 2002) con lo que la afectación sobre el otro es notable.

El capitalismo coloniza mundos, y la antropología los conocimientos de esos mundos. Por esa razón, el dilema ético de la disciplina tiene una carga histórica y una deuda por saldar. La metodología y la investigación tienen influencia en la transformación reflexiva y en la práctica, y en esto la ética no es solo una valoración de potenciales perjuicios sino una reflexión ontológica que lleva a preguntarnos por la naturaleza de las relaciones entre los actores de conocimiento y el alcance de su interacción.

Vale comprender que la antropología es una expresión objetiva de las relaciones de fuerza entre la sociedad dominante y los pueblos indígenas según Levi-Strauss (como se citó en Vasco, 2002). Aquello conduce a movimientos de poder que movilizan tensiones sociales y reafirman dominios y jerarquías entre clases y sus divisiones. En ese contexto, la ética es una arena donde se debate la relación entre conocimiento y dominación pues la ética del conocimiento es dinámica y denunciante, y cuenta con un rol más activo que normativo en la producción del conocimiento científico.

Cabe discutir, desde la perspectiva de Vasco, cómo las clases dominantes hacen uso del discurso de la ética de la investigación y de la neutralidad y la objetividad científica para imponer un modo de pensar o conocer que beneficie su posición en las relaciones de sujeción. Los estudios sociales de la ciencia advierten de las lógicas de poder inscritas en los programas de investigación y en las tecnologías discursivas aplicadas a la creación de percepciones y realidades no necesariamente identificada con los contextos de investigación.

\section{La crítica a la crítica posmoderna y a la escritura en antropología}

La crítica hecha a las consideraciones éticas también cabe a la efectividad de nuevas demandas como las de las emergencias subjetivas, o los discursos del giro decolonial propios de la crítica y reflexión de la posmodernidad que integra los marcos analíticos de una importante mayoría de los trabajo académicos en antropología. Dice Vasco (2016) que la posmodernidad tiene un "[...] carácter más declarativo que real, entre otras cosas porque la posibilidad de aplicación de los nuevos criterios depende de modificaciones esenciales en la relación del etnógrafo con las sociedades que estudia" (p. 79).

En los discursos posmodernos de crítica cultural en antropología, Vasco encuentra cantos de sirena que esconden en su eco de proposición 
crítica otros modos de dominio que impactan el ejercicio intelectual y las apuestas de los pueblos indígenas por producir sus procesos autónomos de conocimiento.

Los críticos posmodernistas de la cultura dejan para el campo del discurso los rechazos y cuestionamientos que hacen a la autoridad y a la colonialidad del saber. Sin embargo, dicha crítica no se extiende a la realidad y a la praxis en la que ese conocimiento y los sujetos que lo producen son objeto de dominación. Para Vasco, esta pasividad corresponde a que una participación activa y la trasformación en la escala actual de las relaciones del conocimiento llevaría a la pérdida de la autoridad y del reconocimiento que tendría el conocimiento científico y sus portadores.

Los académicos de las ciencias sociales temen ceder el control de la producción a quienes son sus genuinos productores, pues sin la autoridad (y la autoría) sobre el análisis y el conocimiento social los investigadores dejarían de tener la exclusividad y el poder de comunicación sobre los saberes de la otredad. En este sentido, los cuestionamientos a las relaciones de poder pueden ser planteados, pero no ejecutados, pues una transformación en la autoridad del saber entraría a cuestionar la producción y circulación del conocimiento mismo. En consecuencia, "la limpia posmoderna [la crítica] no alcanza para conjurar el mal de ojo [el carácter colonialista] de la etnografía clásica, y por el contrario la refuerza" (Flórez, 2004, p. 41).

La escena posmoderna tiene un campo de juego y aplicación en la escritura (también el visual, entre otros) y el manejo discursivo que en esta se da a las posturas críticas sobre lo social y cultural. Los teóricos actuales cuestionan en la escritura la relación objetivizante entre sujeto investigador y objeto de investigación, aunque estas relaciones de dominación se mantengan o refuercen en la experiencia de investigación así como en la producción académica.

La trampa de la objetividad también se extiende al campo de la escritura. La teoría contemporánea en ocasiones hace de esta un cercado, un escenario desconectado e insensibilizado de la realidad que interpreta. Así, el propósito de la escritura antropológica no es comprender y representar las condiciones de los actores sociales para transformarlas sino justificar las formas discursivas, cargadas de palabras y significados que critican la realidad presente, las formas de la dominación y las prácticas colonialistas del conocimiento, pero que están desprovistas de efectos y sentidos prácticos. La escritura en antropología se presenta en ocasiones como pilas de textos carentes de sensibilidad, que no hacen eco en las realidades y estructuras vitales de quienes producen los discursos de los que son nutridos dichos textos. 
La antropología contemporánea y su elaboración escrita tampoco ha producido otra clase de ejercicios del saber-hacer que contribuyan al desmantelamiento de la categórica y jerárquica relación sujeto-objeto. En su lugar, la antropología contemporánea ha optado por la exacerbación de la escritura crítica pero desconectada de las realidades que "representa". La producción y consumo de textos cada vez más especializados opera más en términos de transacción del mercado académico que por una interrelación entre los actores del saber. La producción del conocimiento y las tecnologías del texto escrito operan como un sofisma, donde todo cambia (en la escritura, en tanto mercancía) para que nada cambie (en la realidad y en su funcionamiento).

Al final, la producción posmoderna de discursos no dista mucho -en su capacidad lesiva- de la etnografía colonialista, pues al igual que el trabajo de campo, el modelo de la escritura antropológica contemporánea toma al otro como excusa para producir elucubraciones donde la miseria, la exclusión y la pena del otro son el sostén de los programas de investigación que no solucionan estos conflictos, pero sí dan con qué mantener a la antropología y a los escribanos que componen su crítica cultural.

Esta práctica de la antropología contemporánea, aunque con distintos postulados, es parecida en sus efectos a la cuestionada antropología de sillón del siglo XIX. Los antropólogos contemporáneos retornaron a la comodidad acrítica del sillón para producir crítica discursiva y reflexiva pero rara vez transformadora.

Vasco encuentra que la antropología contemporánea -o posmoderna que es como la define- evita la función social y el sentido del conocimiento que moviliza. Por tanto, la apuesta científica y política de un conocimiento situado y comprometido con los pueblos y las culturas que investiga es confrontar y cuestionar el desarrollo y alcance que la crítica y la producción del antropólogo de sillón formulan.

Con tal propósito, Vasco encuentra pertinente hacerse de nuevo preguntas de base que dirijan la capacidad de comprensión y de acción de la disciplina, entre estas destaca: ¿Antropología para quién? ¿A quién debe servir la antropología? Vasco propone que el eje de esa discusión no ha de estar en la reflexión teórica sino en la práctica de transformación o de desarrollo de los actores objeto de las etnografías.

A pesar de esto, no hay que desconocer que la propuesta que sostiene buena parte de la escritura contemporánea ha influido, en tanto crítica de la cultura, para desvirtuar el predominio del etnógrafo en el trabajo de campo. Esta revisión generó un impacto: el objeto idealizado de la antropología desapareció. El canon del buen salvaje o el informante neutro se 
transformó en un discurso, o en una voz extraída de la experticia hermética del antropólogo.

A partir de esto, se deben cuestionar los presupuestos en los que se sostiene el trabajo de campo y replantear los alcances, y especialmente el tipo de relaciones que en torno a este se constituyen. A eso le apuesta el replanteamiento del trabajo de campo de Vasco, porque "es en el replanteamiento de su papel en relación con un proceso de cambio social heterogéneo e irregular que se debe ver su experimentación de la etnografía como 'relación social'"' (Flórez, 2004, p. 33).

\section{El antropólogo y su desfase como sujeto: el problema del compromiso y la confrontación}

La ruptura entre antropología y realidad parte de otra separación previa dentro de la disciplina. Vasco critica cómo el ejercicio académico en antropología sufre un desfase entre personalidad y profesión que va en detrimento de la capacidad de acción del antropólogo. La trampa de la objetividad que Vasco denuncia ha obligado a que el mismo antropólogo sufra un distanciamiento de sí mismo cuando elabora sus problemas de investigación. Aun en los tiempos de la crisis de la representación y del cuestionamiento a la objetividad cientificista, la proximidad y el compromiso con las poblaciones -y de paso consigo mismo- se rechazan o se ignoran.

El antropólogo y su personalidad emergen, pero anclados a un tributo por la auto-referencia y por la vanidad de ser autor, de exaltar el yo escritural. Dicha vanidad no emerge de la autoridad creativa, tampoco del clásico atributo del "yo estuve ahí" que se abroga el trabajo de campo, sino de la excesiva contemplación de un discurso con propósitos academicistas, adquirido y ejercido en la formación de un perfil intelectual. Este exalta rasgos del yo testimonial y de la semántica a expensas de la humanidad del antropólogo y la de los sujetos sobre los que se erige su discurso.

Este hecho explica por qué muchos de los temas de la antropología, anclados a raíces profundamente vitales, reciben un tratamiento desconectado de la vida social de donde emergen. En consecuencia, la antropología no se asume como un escenario vivo y pertinente, tampoco el desarrollo de sus temas y mucho menos al profesional, pues este carece de vida y sentido si solo incrusta su ser en las posibilidades del texto escrito y limita su margen de acción a la cadena de argumentación, pero no al contexto de donde emerge el discurso.

El conflicto de la dominación y el desconocimiento del otro no cesan en la aridez del conocimiento antropológico. Si solo se tratase de una disciplina incapaz de movilizar esfuerzos en la realidad de los pueblos que estudia 
y que no puede mantener un sentido y una razón práctica en su campo de acción el problema se resolvería con su desaparición. Sin embargo, la desconexión entre la antropología y la realidad -y entre el antropólogo y el otro- cumple una función clave en las relaciones de poder que nutren las jerarquías de dominación. El desconocimiento del otro sí se hace sentir en la realidad y reafirma modelos de autoridad que distinguen entre quien tiene la potestad para conocer (aunque no movilice el conocimiento) y quienes son objeto de conocimiento. El grado de desconexión de la antropología hace posible que se pueda ser antropólogo e ir lance en ristre contra la diversidad cultural, y que la antropología haga de las diferencias entre culturas y pueblos una excusa para la homogenización del conocimiento.

Prueba de esto es que en la agenda contemporánea de los programas de antropología, se advierte con sospecha el trabajo de los antropólogos que se comprometen con la realidad de la que emergen sus estudios. El trabajo de este tipo de investigador es valorado como un "trabajo de misión", asumiendo que el compromiso o militancia del investigador es un acto anticientífico, pasional y poco ético. Dicha crítica privilegia el tipo de investigación y de verdad científica que asume un paradigma de neutralidad valorativa.

A primera vista, parece que la última mención aquí hecha es equivocada. La denuncia de la ciencia social contemporánea está volcada sobre el reconocimiento de ciudadanías más amplias y plurales, y exige la participación y el compromiso de los académicos con temas de coyuntura o con denuncias sobre los fenómenos oprobiosos; además, resalta las voces de apoyo o de rechazo a determinadas situaciones de la agenda pública de una sociedad.

Sin embargo, nuevamente encontramos que la crítica no se refrenda en la práctica. A quien trata de intervenir de forma amplia y constante se le acusa de militante o antiacadémico y no como un productor de conocimiento científico. Para las ciencias sociales la academia debe denunciar, pero no comprometerse con los problemas neurálgicos de la vida social. Debe mantenerse a raya y no incurrir en situaciones que desborden la capacidad científica y que sean interpretadas como acciones políticas o ideológicas.

La neutralidad del conocimiento científico refrenda su dominio en tiempos donde la participación es un tema sumamente discutido, pero escasamente aplicado. La falta de conexión entre práctica y discurso tiene relación con el hecho de que los investigadores practiquemos la autocensura y sospechemos de nosotros mismos cuando asumimos una posición que no coincida con "el respeto" y la "sana distancia" respecto al mundo social donde tiene sentido el trabajo de campo. Así las cosas, dejamos de participar 
de las formas en que conocen y se reconocen los actores del mundo, y nos perdemos de la oportunidad de creer y crear en los conocimientos y las relaciones que hacen posibles los mundos de la vida social.

\section{El lugar de la autoridad: a modo de conclusión}

Se ha creído que la relación de conocimiento entre teoría y realidad inicia cuando el antropólogo ingresa al lugar de la investigación. Esto se asume como cierto porque el conocimiento científico se basa en una ficticia separación o distanciamiento que hay entre el conocimiento sensible y el conocimiento racional. El conocimiento racional somete al sensible cuando el antropólogo racionaliza las subjetividades de los actores objeto de su conocimiento.

Dichas categorías son ficcionales, el trabajo de campo es un entramado, un lugar liminal. Allí se reúnen las afirmaciones y los miedos del conocimiento racional. Sin embargo, los oficiantes de la antropología hacen como si en el campo de emergencia del conocimiento la razón no fuere transgredida por la sensación. Esto es imposible de sostener, ya que las técnicas del trabajo de campo en antropología reafirman dos tipos de situaciones: 1. Que la presunción de racionalidad y neutralidad del conocimiento son imposibles de mantener en el tiempo, pues el conocimiento es una práctica de relación e interacción con la sensibilidad del otro. 2. Que toda postura que condicione la actividad del conocimiento a juicios exclusivamente racionales, tiene otra motivación distinta a la de conocer, busca mantener las relaciones de poder y dominación.

En esta situación, Vasco propone considerar otros alcances y técnicas para la etnografía. La producción de nuevos entornos de conocimiento debe estar en directa relación con las condiciones bajo las cuales las poblaciones aspiran a producir su conocimiento. Esa producción de conocimiento social está involucrada con las formas culturales y sus dinámicas, es de allí que emerge la innovación. La innovación no se encuentra en la discusión textual sino en la arena donde están creando la vida los actores.

Varios de los pueblos otrora dominados y antropologizados, como los guambianos o los nasas en el suroccidente colombiano, cumplen su propia agenda de investigación, de manera autónoma. En esa situación, el foco de la etnografía debe ser otro y privilegiar el desprendimiento del dominio, pues la autoridad del etnógrafo, vista de manera crítica, es un acto de arrogancia y muy al final, también un acto de peonaje y servidumbre del conocimiento de la ciencia social a los requerimientos del capital. 
Los pueblos indígenas contraponen su vida concreta y su lucha frente a la ambigüedad del discurso de conocimiento del etnógrafo. Cuando los antropólogos han sido más sensibles al conocimiento de los pueblos étnicos, se debe al rol que han desempeñado como solidarios y no tanto a su posición como antropólogos. Ese tipo de relación, que privilegia al colaborador en la creación de conocimiento local antes que al científico, implica conocer y caminar para conocer.

Caminar por la vida y recoger sus conceptos materializados en los caminos, en la historia y en las prácticas, es el método que Vasco propone. En el camino también se recoge y se reconoce. Aquí tienen mucha pertinencia los sentidos y las formas de percepción que la razón instrumental desconoce. Por eso es con los indios que surge el diálogo y también la confrontación. A la forma de llevar esa relación entre conocimiento y realidad es lo que Vasco identifica como una metodología del conocer recorriendo, a esto en los territorios de Guambía es lo que han llamado "recoger los conceptos en la vida" (Vasco, 2002).

El conocimiento de los pueblos indígenas reviste formas concretas. El saber es un saber hacer que se desarrolla en la vida mediante los objetos y el concepto que estos encarnan. Cuando el saber de la gente es el que se asume como verdad queda cuestionada la autoridad etnográfica y queda subordinada su experticia a otro tipo de autoridad, la de las formas autónomas y locales de conocer y pensar. Es en esta base que el antropólogo puede hacer de otro modo la etnografía y afirmar la relación entre conocimiento y pertinencia, entre campo e investigación.

\section{Referencias}

Caviedes, M. (2013). Metodologías que nos avergüenzan: propuesta de una investigación en doble-vía y su efímera influencia en la antropología. Universitas Humanística, 75, 37-61.

Castillejo, A. (2017). La ilusión de la justicia transicional: Reflexiones desde el sur global. Bogotá, Colombia: Ediciones Uniandes.

Castillejo, A. y Reyes, F. (2012). Violencia, memoria y sociedad: debates y agendas en la Colombia actual. Bogotá, Colombia: Editorial Universidad Santo Tomás.

Dagua, A., Aranda, M. y Vasco, L.G. (1998). Guambianos: hijos del aroiris y del agua. Bogotá, Colombia. Cerec.

Escobar, A. (2007). La invención del tercer mundo. Construcción y deconstrucción del desarrollo. Caracas, Venezuela: El perro y la rana Editores.

Flórez, F. (2004). El mal de ojo de la etnografía clásica y la limpia posmoderna. Una apostilla a partir de la antropología de L. G. Vasco. Tabula Rasa 2, 23-46.

Foley, D. y Valenzuela, A. (2005). Critical Ethnography. The Politics of Collaboration. En N. Denzin. y Y. Lincoln (Eds.), The Sage Handbook of Qualitative Research (pp. 217-234). USA: Sage Publications.

Godenzzi, J. (1999). Pedagogía del encuentro. El sujeto, la convivencia y el conocimiento. Bulletin de l'Institut français d'études andines, 28(3), 323-328. 
Gros, C. (2000). Políticas de la etnicidad. Identidad, Estado y modernidad. Bogotá, Colombia: ICANH.

Jimeno, M. (2004). La vocación crítica de la antropología latinoamericana. Maguaré 18, 33-58.

Jimeno, M., Pabón, C., Varela, D. y Díaz, I. (2016). Etnografías contemporáneas III: las narrativas en la investigación antropológica. Bogotá, Colombia: CES Universidad Nacional de Colombia.

Pardo, M. (2007). El construir andando de Vasco. Tabula Rasa 6, 15-17.

Malinowski, B. (1986). Los argonautas del Pacífico Occidental. Barcelona, España: Editorial Planeta.

Rappaport, J. (2000). La política de la memoria. Interpretación indígena de la historia en los andes colombianos. Popayán, Colombia: Universidad del Cauca.

Restrepo, E. (2006). Diferencia, hegemonía y disciplinación en Antropología. Universitas Humanística, 62, 43-70.

Restrepo, E. (2011). Modernidad y diferencia. Tabula Rasa 14, 125-154.

Restrepo, E. y Rojas, A. (2010). Inflexión Decolonial. Popayán, Colombia: Universidad del Cauca y Instituto Pensar.

Rosaldo, R. (2000). Cultura y verdad. La reconstrucción del análisis social. Quito, Ecuador: Abya-Yala.

Sandt, J. (2012). Detrás de la máscara del reconocimiento. Defendiendo el territorio y la autonomía indígena en Cxab Wala Wike (Jambaló, Colombia). Popayán: Universidad del Cauca.

Tocancipá-Falla, J. (2016). Introducción: antropologías en Colombia. Retrospectiva y prospectiva. En J. Tocancipá-Falla. (Comp), Antropologías en Colombia. Tendencias y debates (pp. 17-62). Popayán, Colombia: Universidad del Cauca.

Vargas, I. (2016). ¿Cómo se concibe la etnografía crítica dentro de la investigación cualitativa? Revista electrónica Educare 20(2), 1-13.

Vasco, L. G. (2002). Entre selva y páramo. Viviendo y pensando la lucha india. Bogotá, Colombia: ICANH.

Vasco, L.G. (2006). De unas y otras cosas alrededor de la metodología. Charla a estudiantes en la Universidad Externado de Colombia. [Documento Inédito]

Vasco, L.G. (2006). Entrevista a Luis Guillermo Vasco Uribe. Realizada por Elizabeth Cunin. Antípoda, 2, 17-42.

Vasco, L.G. (2007). Así es mi método en etnografía. Tabula Rasa, 6, 19-52.

Vasco, L.G. (2012). Hacia una ciencia social al servicio del pueblo. Charla inaugural del seminario de postgrado "Textos y contextos de las Teorías antropológicas contemporáneas". Maestría en Antropología Social. FLACSO, Buenos Aires".

Vasco, L.G. (2016). 50 años con los indios. La vida de un etnógrafo. Presentación transcrita por el grupo de estudios etnográficos. Bogotá, Colombia: Pontificia Universidad Javeriana.

Vasco, L.G. (s.f.). Algunas notas sobre Molano y el mito. A propósito de "Los años del tropel" de Alfredo Molano. Documento sin datos de edición.

Viveiros de Castro, E. (2010). Metafísicas caníbales. Líneas de antropología postestructural. Buenos Aires, Argentina: KATZ. 